\title{
Brain Natriuretic Peptide is a Predictor of Cardiac Thrombus in Critically III Acute Ischemic Stroke Patients
}

\author{
Hossam A. Mowafy, Hossam El Sherif, Khaled A. Wahab, Nora I. Abbas, Gihan El Hilaly, Doaa A. Elgohary* \\ Department of Critical Care, Faculty of Medicine, Cairo University, Cairo, Egypt
}

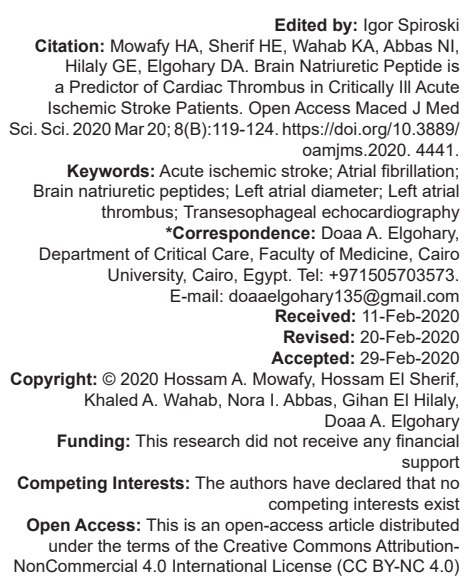

Edited by: Igor Spirosk $\begin{aligned} \text { Edited by: Igor Spiroski } & \\ \text { Citation: Mowafy HA, Sherif HE, Wahab KA, Abbas NI } & \end{aligned}$ Hilaly GE, Elgohary DA. Brain Natriuretic Peptide is Ailaly GE, Elgohary DA. Brain Natriuretic Peptide is
a Predictor of Cardiac Thrombus in Critically III Acute
Ischemic Stroke Patients. Open Access Maced J Med Sci. Sci. 2020 Mar 20; 8(B):119-124. https://doi.org/10.3889/ Keywords: Acute ischemic oamjms.2020.4441. Brain natriuretic peptides; Left atrial diameter; Left atria thrombus; Transesophageal echocardiography "Correspondence: Doaa A. Elgohary, University, Cairo, Egypt. Tel: +971505703573 E-mail: Egypt. Tel: +971505703573 mail: doaaelgohary135@gmail.com Received: 11-Feb-2020 Revised: 20-Feb-2020 Copyright: ๑ 2020 Hossam A. Mowafy, Hossam El Sherif, Khaled A. Wahab, Nora I. Abbas, Gihan EI Hilaly, Doaa A. Elgohary Funding: This research did not receive any financial Competing Interests: The authors have declared that no Open Access: This is an open-access article distributed under the terms of the Creative Commons Atributionunder the terms of the Creative Commons Attribution-
NonCommercial 4.0 International License (CC BY-NC 4.0)

\begin{abstract}
CONTEXT: Plasma brain natriuretic peptide (BNP) levels are elevated in patients with acute ischemic stroke, particularly when accompanied by atrial fibrillation (AF). Plasma BNP might be a useful marker of vulnerability to thromboembolism in non-valvular AF patients.

AIM: The aim of the present study was to assess whether the BNP level can serve as a biomarker of the left atria (LA) thrombus in AF patients with acute ischemic stroke.

SETTINGS AND DESIGN: This was a multicenter prospective cohort study.

PATIENTS AND METHODS: Thirty AF patients with acute ischemic stroke were included in the study. Their transesophageal echocardiography (TEE) and BNP were assessed.

RESULTS: There was a positive significant relation between serum BNP levels and LA thrombus detection by TEE. BNP with a cutoff value $>498 \mathrm{pg} / \mathrm{l}$ can be used as a diagnostic biomarker for the presence of the LA thrombus. A significant positive correlation existed between serum BNP and LA diameter. Furthermore, a statistically significant positive correlation between serum BNP and AF rate and duration was found in all patients. In addition, a statistically significant inverse correlation was detected between serum BNP and direct bilirubin, international normalized ratio, and albumin. A statistically significant positive correlation existed between serum BNP and prothrombin concentration.

CONCLUSION: BNP can be a good diagnostic biomarker for the detection of the LA thrombus in chronic AF patients with acute ischemic stroke.
\end{abstract}

\section{Introduction}

Atrial fibrillation (AF) patients with ischemic stroke or transient ischemic attacks (TIAs) are at high risk for recurrent stroke. Patients with the left atrial (LA) thrombus are at particularly high risk for thromboembolic events, the incidence of which can be reduced by anticoagulant agents.

Therefore, early identification of the LA thrombus in acute ischemic stroke is important to prevent further brain ischemia [1].

Although transesophageal echocardiography (TEE) is a useful clinical tool for identifying actual thrombi and visualizing spontaneous echo contrast in AF patients, its semi-invasive nature precludes its application for patients with acute stroke [2].

Brain natriuretic peptide (BNP) is 32 amino acids polypeptide with a 17 amino acid ring structure that was named after isolation from the porcine brain in 1988. It is a diuretic and vasodilatory factor that is released mainly from the ventricular myocardium. BNP was shown to be a sensitive marker of congestive heart failure. Plasma BNP levels are elevated in patients with acute ischemic stroke, particularly when accompanied by AF. Plasma BNP might be a useful marker of vulnerability to thromboembolism in non-valvular $\mathrm{AF}$ patients [3].

\section{Aim of the work}

The aim of the present study was to assess whether BNP levels can serve as a diagnostic biological marker of thrombus in AF patients with acute ischemic stroke. Study group - it consisted of 30 chronic AF patients who had acute ischemic stroke.

The study group was further divided into subgroups according to the results of TEE into either TEE positive or TEE negative. All participants were subjected to a full and careful history taking and clinical examination and echocardiography. Echocardiography was carried out using transthoracic echocardiography with $\mathrm{M}$ mode, two D mode, and Doppler study. In TEE, the key view is the two-chamber view to see the LA appendage (LAA), and it can be useful to study the appendage at $\sim 90^{\circ}$ to this view to see the pectinate muscles in more details. The scan plane can be rotated 
to $\sim 140^{\circ}$ while maintaining the appendage in the center of the image [4].

\section{Laboratory tests}

Samples of BNP were withdrawn on the same day of doing TEE and were measured using the fluorescent immune-sorbent assay. The test principle is as follows:-

The microtiter plate provided in the kit comes pre-coated with an antibody specific to BNP. Samples are then added to the appropriate microtiter plate wells with a biotin-conjugated antibody specific to BNP. Next, avidin conjugated to horseradish peroxidase is added to each microplate well and incubated. After 3,3',5,5'-tetramethylbenzidine substrate solution is added, only those wells that contain BNP, biotin-conjugated antibody, and enzyme-conjugated avidin exhibit a change in color. The enzyme-substrate reaction is terminated by the addition of a sulfuric acid solution and the color change is measured spectrophotometrically at a wavelength of $450 \pm 10 \mathrm{~nm}$. BNP concentration in the samples is then determined by comparing the optical density of the color of the samples to the standard curve [5].

\section{Statistical data}

Data were analyzed on an IBM computer using Statistical Package for the Social Sciences, version 12 as follows:

(1) Quantitative variables were described as mean, standard deviation (SD), and range.

(2) Qualitative variables were described as number and percentage.

(3) The Chi-square-test was used to compare qualitative variables between groups.

(4) The unpaired t-test was used to compare quantitative variables, in parametric data (SD $<50 \%$ mean).

(5) The one-way analysis of variance test was used to compare more than two groups as regard quantitative variables.

(6) Spearman's correlation coefficient test was used to rank variables versus each other positively or inversely.

(7) Receiver operator characteristic curve was used to find out the best cutoff value and validity of a certain variable [6].

\section{Results}

There was a positive significant relation between serum BNP levels and presence of the LA thrombus, as documented by TEE. BNP with a cutoff value $>498 \mathrm{pg} / \mathrm{l}$ can be used as a diagnostic biomarker for the presence of the LA thrombus.

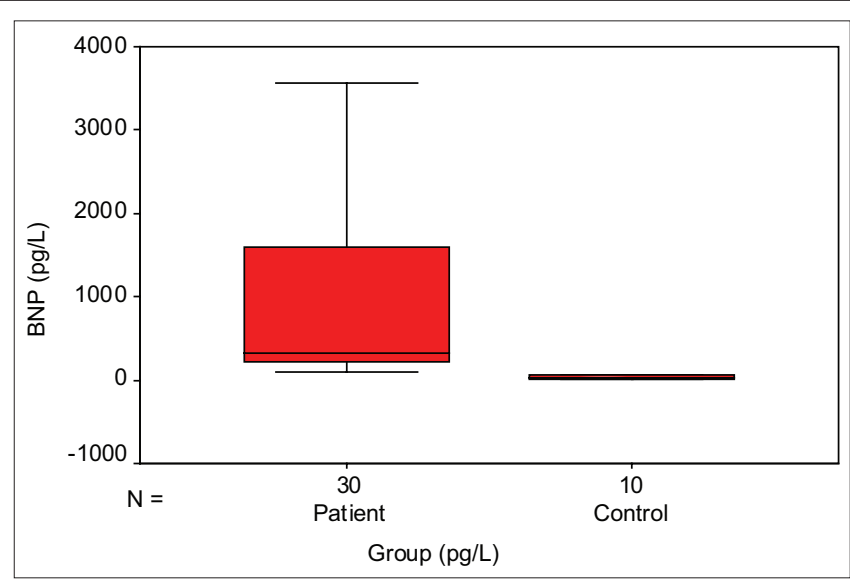

Figure 1: Patients with transesophageal echocardiography (TEE)positive group having statistically significantly higher level of serum brain natriuretic peptide compared with the TEE-negative group $(p<0.001)$

A significant positive correlation existed between serum BNP and LA diameter. In addition, a statistically significant positive correlation between serum BNP and AF rate and duration was found in all patients.

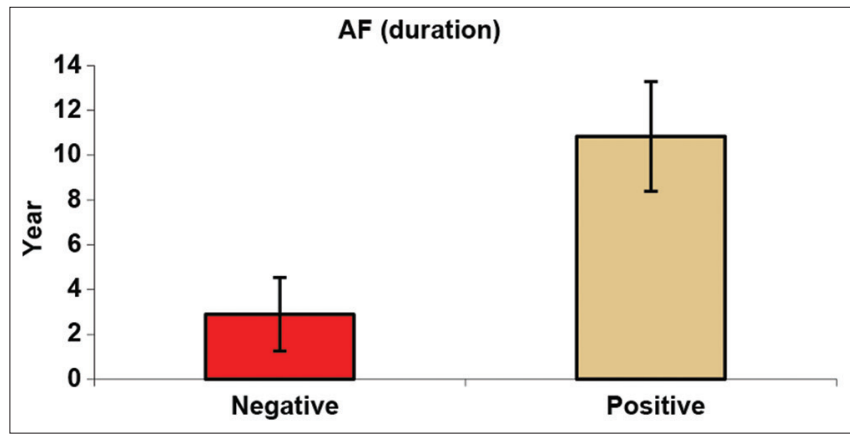

Figure2: Correlation between serum brain natriuretic peptide levels and atrial fibrillation duration

A statistically significant inverse correlation was detected between serum BNP and direct bilirubin, international normalized ratio, and albumin. A statistically significant positive correlation existed between serum BNP and prothrombin concentration (Figures 1-4 and Tables 1-11).

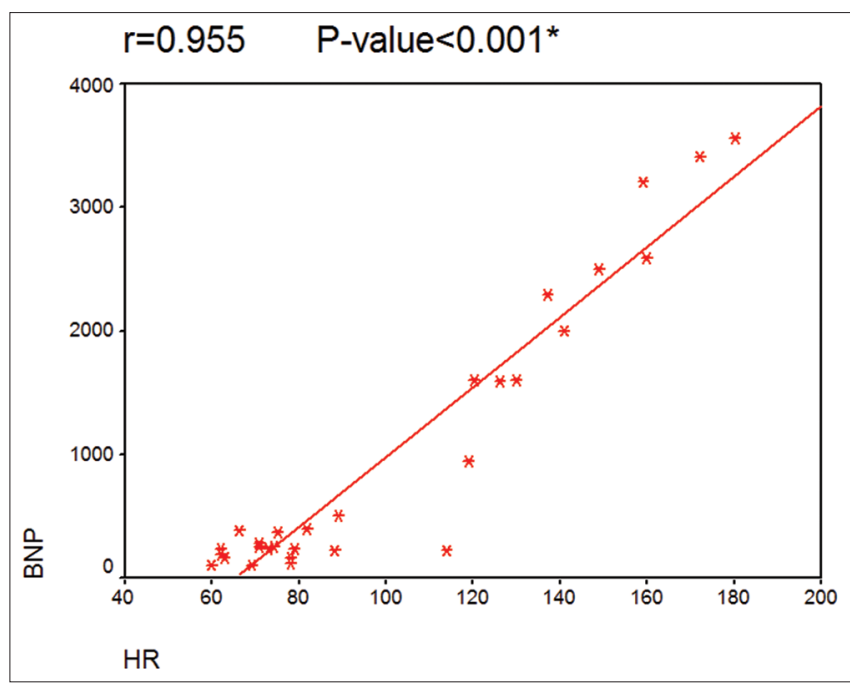

Figure 3: Validity of serum brain natriuretic peptide in the prediction of transesophageal echocardiography result 


\section{Discussion}

The current study agrees with Okada et al. who were trying to find a relation between serum BNP levels and LA thrombus in chronic AF patients admitted with acute ischemic stroke (within 7 days) of an ischemic stroke or TIA, serum BNP was withdrawn at the day of TEE; the results were as follows:

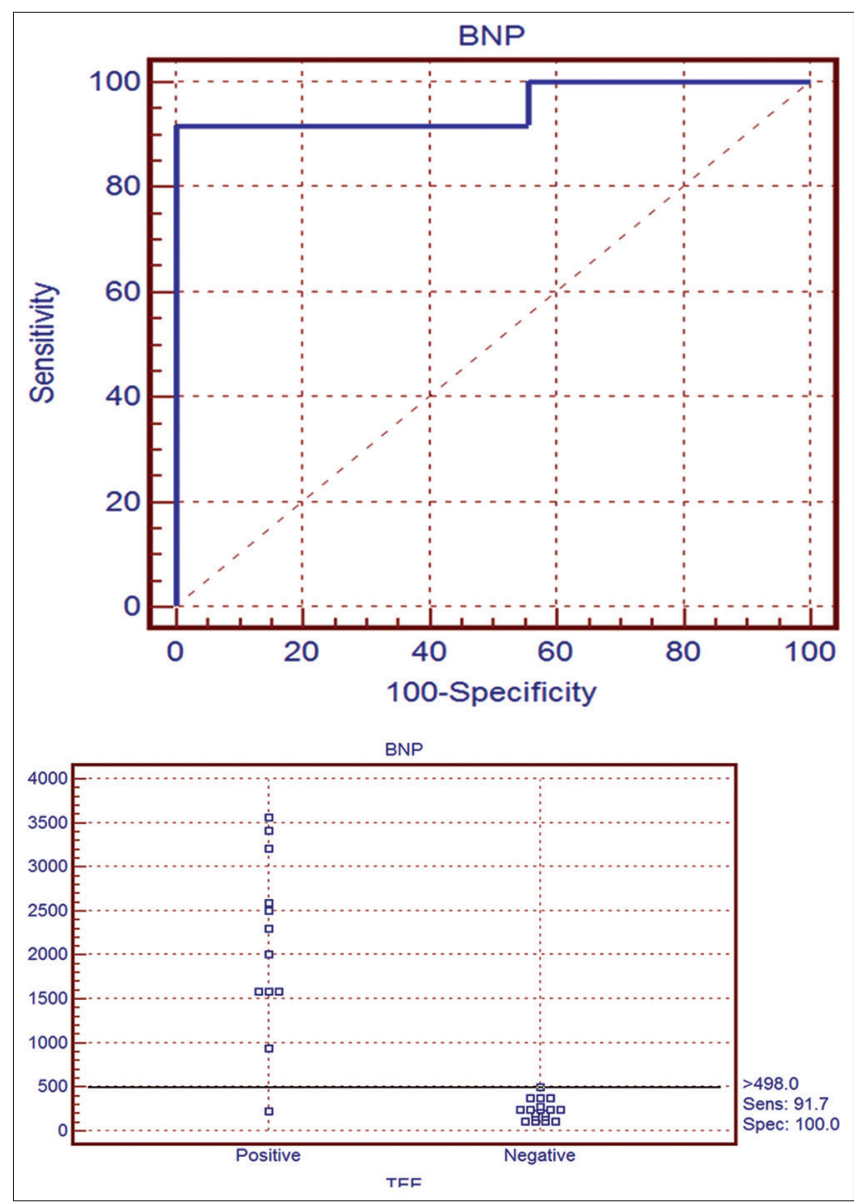

Figure 4: Validity of serum brain natriuretic peptide in the prediction of transesophageal echocardiography result

Table 1: Demographic data of patients

\begin{tabular}{llll}
\hline Variables & Patient (\%) & Control (\%) & p-value \\
\hline Gender & & & \\
Female & $16(53.33)$ & $3(30)$ & 0.195 \\
Male & $14(46.67)$ & $7(70)$ & \\
Age (Mean $\pm S D)$ & $58.7 \pm 10.462$ & $28.7 \pm 5.774$ & $<0.001^{*}$ \\
\hline SD: Standard deviation. & & &
\end{tabular}

TEE-positive group $(n=17)$, serum BNP was higher compared with the TEE-negative group $(n=50)$ (307.3 \pm 270.6 vs. $146.5 \pm 119.5 \mathrm{pg} / \mathrm{l}$, respectively) $(\mathrm{p}$ $=0.012$ )

Table 2: Distribution of the studied cases as regard clinical data

\begin{tabular}{ll}
\hline Clinical data & $\mathrm{n}(\%)$ \\
\hline Smoking & $14(46.67)$ \\
IHD & $8(26.67)$ \\
HTN & $14(46.67)$ \\
DM & $21(70)$ \\
Dyslipidemia & $21(70)$ \\
\hline DM: Diabetes mellitus, HTN: Hypertension, IHD: Ischemic heart disease. &
\end{tabular}

Furthermore, they found that TEE-positive patients had statistically significant higher age than those of TEE-negative patients $(76.5 \pm 9.5$ vs. $55.4 \pm$ 11.7 years, respectively) $(p \leq 0.001)$.

Table 3: Distribution of the studied patients as regard transesophageal echocardiography results (left atrial thrombus)

\begin{tabular}{ll}
\hline TEE & $\mathrm{n}(\%)$ \\
\hline Negative & $18(60)$ \\
Positive & $12(40)$ \\
Total & $30(100)$ \\
\hline TEE: Transesophageal echocardiography. &
\end{tabular}

This comes in agreement with the findings of our study: The mean age in the TEE-positive group was $68.167 \pm 9.20$ years compared with $52.389 \pm$ 5.14 in the TEE-negative group $(p<0.001)$. A positive correlation existed between serum BNP and age $(r=0.562$ and $p<0.001)$ [7].

Table 4: Serum brain natriuretic peptide in patients with acute ischemic stroke

\begin{tabular}{llllll}
\hline Group & BNP $(\mathrm{pg} / \mathrm{L})$ & & & & \\
\cline { 2 - 6 } & Range & Median & Interquartile range & Mean rank & p-value \\
\hline Patient & $103.000-3557.000$ & 322.500 & 1491.500 & 25.500 & $<0.001^{*}$ \\
Control & $8.00-63.000$ & 27.000 & 45.500 & 5.500 & \\
\hline BNP: Brain natriuretic peptide. & & & &
\end{tabular}

Doukky et al. conducted a retrograde cohort study of 297 consecutive cases with non-valvular AF who underwent a clinically indicated TEE for the LA thrombus detection. They aimed to investigate whether the plasma BNP is predictive of the LAA thrombus and stroke or not. Nineteen (6.4\%) patients were found to have LA thrombus by TEE and the remaining $278(93.6 \%)$ were free of LA thrombus.

Table 5: Comparison between transesophageal echocardiography positive and negative groups as regard serum brain natriuretic peptide

\begin{tabular}{llll}
\hline Group & BNP $(\mathrm{pg} / \mathrm{L})$ & p-value \\
\cline { 2 - 3 } & Range & Mean \pm SD & \\
\hline Negative & $103.000-489.000$ & $237.611 \pm 112.014$ & $<0.001^{*}$ \\
Positive & $825.000-43757$ & $2125.333 \pm 1005.918$ & \\
\hline BNP: Brain natriuretic peptide. & &
\end{tabular}

There was a stepwise increase in the prevalence of the LA thrombus with an increasing BNP level. All patients with positive TEE had serum BNP of at least $500 \mathrm{pg} / \mathrm{l}$ and a decreased heart rate. However, in their study, there was no statistically significant difference as regard mean age in the TEE-positive group $(n=19)$ and the TEE-negative group $(n=278)$ (66 \pm 13 vs. $62 \pm 14$ years, respectively) $(p=0.37)$ [8].

Table 6: Comparison between normal and abnormal left atrial diameter and serum brain natriuretic peptide

\begin{tabular}{llllll}
\hline LA echo & BNP $(\mathrm{pg} / \mathrm{L})$ & & & \multicolumn{2}{c}{ p-value } \\
\cline { 2 - 5 } & Range & Median & Interquartile range & Mean rank & \\
\hline Normal & $103.000-195.000$ & 118.000 & 56.000 & 4.000 & $<0.001^{*}$ \\
Abnormal & $218.000-3557.000$ & 498.000 & 2050.000 & 19.000 & \\
\hline BNP: Brain natren
\end{tabular}

BNP: Brain natriuretic peptide, LA: Left atrial.

Sakai et al. studied 221 patients (141 men; mean age: 72.9 years) to evaluate the role of BNP in distinguishing cardioembolic (CE) stroke from non-CE stroke. The median of the NIHSS score on admission was $6(2-15.75)$. The mean \pm SD time interval from stroke onset to blood sample collection was $8.2 \pm 7.4 \mathrm{~h}$, and the mean \pm SD BNP level was $214.5 \pm 358.3 \mathrm{pg} / \mathrm{ml}$. 
Table 7: Correlation between serum brain natriuretic peptide and age, left atrial diameter, atrial fibrillation duration, and atrial fibrillation rate

\begin{tabular}{lll}
\hline Correlations & $\mathrm{BNP}(\mathrm{pg} / \mathrm{L})$ & $\mathrm{p}$-value \\
\cline { 2 - 3 } & $\mathrm{R}$ & $0.001^{*}$ \\
Age (years) & 0.562 & $<0.001^{*}$ \\
LA echo & 0.872 & $<0.001^{*}$ \\
AF (duration) & 0.902 & $<0.001^{*}$ \\
HR (beat/min) & 0.955 &
\end{tabular}

According to the results of BNP, they divided the patients into two groups: The high BNP level group, which included $81(36.7 \%)$ patients and the low BNP level group, which included 140 (63.3\%) patients. They found that the patients of the high BNP level group were of CE origin, mostly AF with variable types. They also found that there was a statistically significant difference between the high BNP level (CE positive) group and the low BNP level (CE negative) group as regard age $(77.7 \pm 12.0$ vs. $70.1 \pm 12.0$, respectively $)$ $(p<0.001)[9]$.

Table 8: Correlation between serum brain natriuretic peptide and laboratory data

\begin{tabular}{lll}
\hline Correlations & BNP $(\mathrm{pg} / \mathrm{L})$ & \\
\cline { 2 - 3 } & $\mathrm{R}$ & -value \\
\hline Bil T $(\mathrm{mg} / \mathrm{dL})$ & -0.350 & $0.058^{*}$ \\
Bil D $(\mathrm{mg} / \mathrm{dL})$ & -0.392 & $0.032^{*}$ \\
PT $(\mathrm{s})$ & -0.348 & $0.059^{*}$ \\
INR & -0.373 & $0.042^{*}$ \\
PC $(\%)$ & 0.442 & $0.014^{*}$ \\
Uric acid $(\mathrm{mg} / \mathrm{dL})$ & 0.350 & $0.058^{*}$ \\
Albumin $(\mathrm{g} / \mathrm{dL})$ & -0.760 & $<0.001^{*}$ \\
\hline BNP: Brain natriuretic peptide. & &
\end{tabular}

Okada et al. [6] found no effect of sex on the stroke or thrombus formation or the serum BNP level.

Table 9: Validity of serum brain natriuretic peptide in the prediction of transesophageal echocardiography result

\begin{tabular}{llllll}
\hline ROC curve & \multicolumn{1}{l}{} \\
\hline Cutoff & Sens. & Spec. & PPN & NPV & Accuracy \\
\hline$>498^{*}$ & 91.7 & 100.0 & 100.0 & 94.7 & 0.954 \\
\hline That BNP is considered highly valid in prediction with the left atrial thrombus, with sensitivity of $91 \%$ at cutoff
\end{tabular}

That BNP is considered highly valid in prediction with the left atrial thrombus, with sensitivity of $91 \%$ at cutoff value 498 pg. NPV: Negative predictive value, PPV: Positive predictive value, ROC: Receiver operating characteristic.

However, Sakai et al. found a significant difference as regard sex between the high and low BNP level groups. The frequency of the female sex in the high BNP group was $44.4 \%$ compared with $31.4 \%$ for the low BNP group $(p<0.001)[9]$.

Table 10: Effect of atrial fibrillation duration on the serum level of brain natriuretic peptide according to the equation $B N P=-406.764+230.681$ AF duration, with the $R$ square of $81 \%$

\begin{tabular}{|c|c|c|c|c|c|}
\hline \multirow[t]{2}{*}{ Model } & \multirow{2}{*}{$\begin{array}{l}\text { Unstandardized } \\
\text { coefficients }\end{array}$} & \multicolumn{2}{|c|}{$\begin{array}{l}\text { Standardized } \\
\text { coefficients }\end{array}$} & \multirow[t]{2}{*}{$\mathrm{p}$-value } & \multirow[t]{2}{*}{ R-square } \\
\hline & & Std. error & Beta & & \\
\hline Constant & -406.764 & 155.577 & & $0.014^{*}$ & $81.4 \%$ \\
\hline AF (duration) & 230.681 & 20.852 & 0.902 & $<0.001^{*}$ & \\
\hline
\end{tabular}

In their study, Okada included 17 TIA patients, with a mean age of $76.5+11.1$ years. There was a positive correlation $(r=0.872)$ between LA diameter and serum BNP levels with $p<0.001$. This means that serum BNP is elevated with the LA dilatation, which increased the risk for LA thrombus [7].
Table 11: Effect of LA diameter on the serum brain natriuretic peptide level according to the equation $\mathrm{BNP}=-6130.826+1476.889$ LA diameter, with $\mathrm{R}$ square of $76 \%$

\begin{tabular}{llllll}
\hline Model & $\begin{array}{l}\text { Unstandardized } \\
\text { coefficients }\end{array}$ & \multicolumn{2}{l}{$\begin{array}{l}\text { Standardized } \\
\text { coefficients }\end{array}$} & p-value & R-square \\
\cline { 2 - 3 } & B & Std. error & Beta & & \\
\hline Constant & -6130.826 & 763.304 & & $<0.001^{*}$ & $76 \%$ \\
LA echo & 1476.889 & 156.810 & 0.872 & $<0.001^{*}$ & \\
\hline BNP: Brain natriuretic peptide, LA: Left atrial. & & &
\end{tabular}

In agreement with the results of the present study, Doukky et al. [8] also showed that the BNP level had highly statistically significant positive correlation with LA size (coefficient $r=0.33$ and $p=0.002$ ). Moreover, Obel et al. showed that an increasing ventricular rate was associated with significantly lower peak inflow, peak outflow, mean inflow, and mean outflow velocities as well as with a lower time velocity interval of the LAA filling and emptying velocities. This effect was noted at rates of 60 beats/min compared with both 120 and 150 beats/min [10], [11].

The findings of the present study were in agreement with those of Shimizu et al.; they assessed a possible relationship between LAA function and plasma BNP levels in non-valvular AF. The study consisted of 34 patients with chronic non-valvular AF (age: $69 \pm 9$ years) who underwent a TEE study and plasma BNP measurement. The patients were divided into two groups: Patients with and patients without a history of CE events (stroke) or echocardiographic evidence of thrombus into the embolic positive ( $E$ positive) group and the embolic negative (E negative) group, respectively. The patients of the E-positive group demonstrated greater impairment of the LAA velocity and higher plasma BNP levels than did those of the E-negative group. There was a statistically significant difference as regard LAA velocity (LAA velocity of $12 \pm$ 6 in the positive group vs. $31 \pm 17 \mathrm{~cm} / \mathrm{s}$ in the negative group, $p<0.05$ ) [8], [12].

The findings of the current study were in agreement with those of Okada et al. who reported that the TEE-positive group had statistically significant higher serum BNP levels compared with the TEEnegative group ( $307.3 \pm 270.6$ vs. $146.5 \pm 119.5 \mathrm{pg} / \mathrm{l}$, respectively; $p=0.012$ ). This was in agreement with our results where a statistically significant difference was found between serum BNP in TEE-positive and TEEnegative groups $(2125.333 \pm 1005.918$ vs. $237.611 \pm$ 112.046 pg/l, respectively; $p<0.001$ ) [7].

In addition, the findings of the present study were in agreement with those of Doukky et al. who found that serum BNP was highly elevated in patients with LA thrombus TEE positive $(n=19)$ compared with patients with LA thrombus TEE negative $(n=278)$, with a statistically significant difference (1949 \pm 1787 vs. 819 $\pm 1067 \mathrm{pg} / \mathrm{l}$, respectively; $p=0.001)$. They concluded that the serum BNP level is predictive of LA thrombus in patients with non-valvular AF and may have a better discriminatory capacity than that of the CHADS2 and CHADS2-VASc [8]. 
Sakai et al. found that the patients in the high $B N P$ group were of $C E$ in origin, mostly $A F$ with variable types. CE occurred in $59(72.8 \%)$ patients in the high BNP group $(n=81)$ and in $17(12.1 \%)$ patients in the low BNP group $(n=140)$, with $p<0.001$ [8].

Of the 21 patients without CE who had high BNP levels, seven had chronic renal failure, five had old myocardial infarction, and two were cardiomyopathic (22 patients of high BNP group were of non-CE stroke and 123 patients of the low BNP group were of non-CE stroke). A BNP level of $142.5 \mathrm{pg} / \mathrm{ml}$ was identified as the optimal cutoff value with a sensitivity of $77.6 \%$ and specificity of $84.8 \%$. This is in agreement with the findings of the present study; however, a higher cutoff level of more than $498 \mathrm{pg} / \mathrm{ml}$ increased sensitivity to $91.7 \%$ and specificity to $100 \%$ [9].

Shimizu et al. reported that the atrium is the main source of BNP in AF patients without overt heart failure. Thirteen chronic non-valvular AF patients with a history of CE events (stroke) or echocardiographic evidence of thrombus (E-positive group) were compared with $21 \mathrm{AF}$ patients without complications (neither echocardiographic evidence of the LA thrombus nor any CE events) (E-negative group). The result of their study showed that the patients of the E-positive group demonstrated greater impairment of the LAA velocity and higher plasma BNP levels than did those of the E-negative group. Their study showed a statistically significant difference as regard serum BNP between the two groups $(126 \pm 53$ vs. $86 \pm 45 \mathrm{ng} / \mathrm{l} ; \mathrm{p}<0.05)$. They concluded that BNP was a significant predictor of thromboembolism. This is in agreement with our results; a statistically significant difference was detected in our study between serum BNP in TEE-positive and TEEnegative groups $(2125.333 \pm 1005.918$ vs. $237.611 \pm$ $112.046 \mathrm{pg} / \mathrm{l}$, respectively; $\mathrm{p}<0.001)$. Moreover, our results were in agreement with those of Maruyama et al. who studied 231 patients with acute ischemic stroke. The highest serum BNP level was found in patients with $\mathrm{CE}$ stroke due to AF. The BNP levels positively correlated with CHADS2 scores in AF patients (202 [120-385 pg/l]) with $p<0.001$ [12], [13].

The results of the current study were in agreement with those of Zhixin et al. who studied 142 acute ischemic stroke patients and made their discharge diagnosis and stroke etiologic subtypes according to TOAST criteria: LAA, CE, small artery occlusion, stroke of other determined etiology, and stroke of other undetermined etiology. Of the 142 patients, $35.92 \%$ were diagnosed with LAA at discharge, $25.35 \%$ with CE, $27.46 \%$ with small artery occlusion, and $11.27 \%$ with stroke of other determined etiology or stroke of other undetermined etiology. Age, previous cardiac disease, AF, length of the stay, NIHSS on admission, and modified Rankin score on discharge were all significantly higher in the CE patients compared with those of other subtypes $(p<0.01)$. Moreover, the mean BNP concentration was significantly higher in the CE group than those of other subtypes $(p<0.001)$. The optimal cutoff value, sensitivity, and specificity of the plasma BNP concentration suitable to distinguish CE from non-CE were $66.5 \mathrm{pg} / \mathrm{l}, 75.0 \%$, and $88.7 \%$, respectively [14]. This study showed a good positive correlation among the study groups between serum BNP and AF duration with $p<0.001$ and $r=0.902$. A possible explanation could be that with increased AF duration, the LA becomes more and more dilated because of remodeling. The LA is the main source of $B N P$ in chronic AF, and thus, its level increases with time.

\section{Conclusion}

BNP can be used as a good diagnostic biomarker for the presence of the LA thrombus in chronic non-valvular AF intensive care unit patients admitted with acute ischemic stroke.

\section{References}

1. Hart RG, Pearce LA, Koudstaal PJ. Transient ischemic attacks in patients with atrial fibrillation: Implications for secondary prevention: The European Atrial Fibrillation Trial and Stroke Prevention in Atrial Fibrillation III trial. Stroke. 2004;35(4):94851. https://doi.org/10.1161/01.str.0000120741.34866.1d PMid:14988571

2. Fatkin D, Loupas $T$, Jacobs N, Feneley MP. Quantification of blood echogenicity: evaluation of a semiquantitative method of grading spontaneous echo contrast. Ultrasound Med Biol. 1995;21(9):1191-8. https://doi. org/10.1016/0301-5629(95)02006-3

PMid:8849833

3. Montaner J, Perea-Gainza M, Delgado P, Ribó M, Chacón P, Rosell A, et al. Etiologic diagnosis of ischemic stroke subtypes with plasma biomarkers. Stroke. 2008;39(8):2280-7. https://doi. org/10.1161/strokeaha.107.505354

PMid:18535284

4. Gardin JM, Adams DB, Douglas PS, Feigenbaum H, Forst DH, Fraser AG, et al. Recommendations for a standardized report for adult transthoracic echocardiography: A report from the American society of echocardiography's nomenclature and standards committee and task force for a standardized echocardiography report. J Am Soc Echocardiogr. 2002;15(3):275-90. https://doi. org/10.1067/mje.2002.121536

PMid:11875394

5. Bock JL. Cardiac injury, atherosclerosis, and thrombotic disease. In: McPherson RA, Pincus MR, editors. Henry's Clinical Diagnosis and Management by Laboratory Methods. $23^{\text {rd }}$ ed., Ch. 18. St Louis, MO: Elsevier; 2017. https://doi.org/10.1016/ b978-1-4377-0974-2.00018-x

6. Miller MC, Knapp RG. Clinical Epidemiology and Biostatistics. $3^{\text {rd }}$ ed. Maryland: Williams and Wilkins; 1992.

7. Okada Y, Shibazaki K, Kimura K, Matsumoto N, Iguchi Y, Aoki J, et al. Brain natriuretic peptide is a marker associated with 
thrombus in stroke patients with atrial fibrillation. J Neurol Sci. 2011;301(1-2):86-9. https://doi.org/10.1016/j.jns.2010.10.017

PMid:21094497

8. Doukky R, Gage H, Nagarajan V, Demopoulos A, Cena M, Garcia-Sayan E, et al. B-type natriuretic peptide predicts left atrial appendage thrombus in patients with nonvalvular atrial fibrillation. Echocardiography. 2013;30(8):889-95. https://doi. org/10.1111/echo.12169

PMid:23496263

9. Sakai K, Shibazaki K, Kimura K, Aoki J, Kobayashi K, Fujii S, et al. Brain natriuretic peptide as a predictor of cardioembolism in acute ischemic stroke patients: Brain natriuretic peptide stroke prospective study. Eur Neurol. 2013;69(4):246-51. https://doi. org/10.1159/000342887

PMid:23406829

10. Obel OA, Luddington L, Maarouf N, Aytemir K, Ekwall C, Malik M, et al. Effects of ventricular rate and regularity on the velocity and magnitude of left atrial appendage flow in atrial fibrillation. Heart. 2005;91(6):764-8. https://doi.org/10.1136/hrt.2003.030940 PMid:15894771

11. European Heart Rhythm Association, European Association for
Cardio-Thoracic Surgery, CammAJ, KirchhofP, Lip GY, Schotten U et al. Guidelines for the management of atrial fibrillation: The task force for the management of atrial fibrillation of the European Society of Cardiology (ESC). Eur Heart J. 2010;31(19):2369-429. https://doi.org/10.12968/bjca.2011.6.5.240

PMid:20802247

12. Shimizu H, Murakami $Y$, Inoue $\mathrm{S}$, Ohta $\mathrm{Y}$, Nakamura $\mathrm{K}$, Katoh $\mathrm{H}$, et al. High plasma brain natriuretic polypeptide level asamarker of risk for thromboembolism in patients with non-valvular atrial fibrillation. Stroke. 2002;33:1005-10. https://doi.org/10.1161/ hs0402.105657

13. Maruyama K, Shiga T, lijima M, Moriya S, Mizuno S, Toi S, et al. Brain natriuretic peptide in acute ischemic stroke. J Stroke Cerebrovasc Dis. 2014;23(5):967-72. https://doi.org/10.1016/j. jstrokecerebrovasdis.2013.08.003 PMid:24119617

14. Zhixin $\mathrm{W}$, Lianhong $\mathrm{Y}$, Wei $\mathrm{H}$, Lianda L, Longyuan J, Yingjian Z, et al. The value of the use of plasma B-type natriuretic peptide among acute ischemic stroke patients in a Chinese emergency department. Clin Neurol Neurosurg. 2013;115(9):1671-6. https:// doi.org/10.1016/j.clineuro.2013.02.021

PMid:23518421 